\title{
Experiments on Removal of Hydrophilic Fine Particles in Bubbly Flow
}

\author{
Masatoshi KAWABATA, ${ }^{1,2)}$ Yuichi TSUKAGUCHI, ${ }^{2)}$ Jyungyu KANG, ${ }^{1)}$ Kosuke HAYASHI $^{11}$ and Akio TOMIYAMA ${ }^{1 / *}$ \\ 1) Graduate School of Engineering, Kobe University, 1-1 Rokkodai, Nada, Kobe, Hyogo, 657-8501 Japan. \\ 2) Research and Development Laboratories, Nippon Steel \& Sumitomo Metal Corporation, 16-1 Sunayama, Kamisu, Ibaraki, \\ 314-0255 Japan.
}

(Received on August 22, 2018; accepted on October 17, 2018)

\begin{abstract}
It is commonly believed that the solid oxides, like aluminum inclusions, were easily removed by bubbles because of their poor wettability with molten steel. However the liquid oxides like ladle slags were hard to remove because of their good wettability. The purpose of this study was to reveal the removal rate coefficient of the hydrophilic particles, which simulated liquid oxides in molten steel, in bubbly flows. The water model experiments were carried out. The air was injected into water-particles mixtures in a rectangular tank and the amount of particles included in the mixture overflowed from the tank was measured. The experiments confirmed that bubbles have abilities to bring hydrophilic particles upward even though the particles do not adhere to the bubble interfaces. The hydrophilic particles are entrained into the bubble wake at a certain probability and dragged upward while riding on the liquid flow in the wake. The removal rate coefficient per a bubble increases with the bubble diameter whereas the increase in the number of bubbles deteriorates the efficiency due to the reduction of the wake volume which is effective for particle transportation.
\end{abstract}

KEY WORDS: hydrophilic inclusion; bubble; bubble wake; removal rate coefficient.

\section{Introduction}

Improving the purity of molten steel in the continuous casting is of great importance to realize high quality steel products. Therefore, there have been various engineering processes for removing inclusions in the tundish. Gas injection into molten steel, by which gas bubbles are expected to bring inclusions up to a slag layer at free surface, is one of the promising inclusion removal techniques. ${ }^{1-6)}$

Aluminum inclusions, $\mathrm{Al}_{2} \mathrm{O}_{3}$, have been considered to be attached to bubble interfaces due to their good wettability with molten steel. There are many studies on the mechanism and efficiency of removal of hydrophobic particles. $^{7-15)}$ Reay and Ratcliff ${ }^{8)}$ theoretically investigated the removal efficiency of fine particles by rising bubbles. Their model showed that the decrease in bubble size increases the removal rate. Yoon and $\mathrm{Mao}^{12)}$ modeled the removal of fine particles in a liquid pool as a first-order ordinary differential equation, in which the time derivative of the total number of particles in the liquid pool is assumed to be proportional to the total number of particles itself, and therefore, the proportional coefficient is referred to as the particle removal rate coefficient. The removal rate coefficient is given in terms of the bubble surface area and the probability of particle collection consisting of the collision, adhesion and detachment probabilities. In their model, the

\footnotetext{
* Corresponding author: E-mail: tomiyama@mech.kobe-u.ac.jp DOI: https://doi.org/10.2355/isijinternational.ISIJINT-2018-582
}

collision probability increases with decreasing bubble size and with increasing particle size, which is consistent with Reay's model and other reports. ${ }^{11)}$ Flint and Howarth ${ }^{16)}$ deduced the efficiency of collision between a bubble and a particle in the Stokes and potential flow regimes. The collision efficiency depends on two dimensionless parameters: the particle settling velocity scaled by the bubble velocity and the particle Reynolds number. They pointed out based on the model that the collision efficiency is governed by the former and increases with decreasing bubble size when the particle size is small, whereas both parameters affect the collision efficiency, which increases with bubble size, when the particle size is large.

The Yoon-Mao model and single-bubble flotation experiments ${ }^{12)}$ implied that the hydrophobic force plays a dominant role in particle removal by bubbles. Zheng et al. ${ }^{13)}$ carried out particle removal experiments and also pointed out the importance of the hydrophobicity of particle in removal efficiency. Pan et al. ${ }^{9)}$ investigated the effects of particle properties on the removal efficiency. They divided the particle transportation process into the particle transport from bulk liquid to the bubble interface due to adhesion and that in the bulk liquid due to the liquid flow caused by bubbles. Their experiments revealed that, for hydrophobic inclusions like $\mathrm{Al}_{2} \mathrm{O}_{3}$, the latter process governs the removal rate since the former proceeds much more rapidly.

Slag inclusions may not attach themselves to bubble interfaces since their wettability with molten steel is poor. In contrast to the studies on removal of hydrophobic particles, 
only a few studies on the effects of bubbles on removal of hydrophilic particles have been carried out. Li et al. ${ }^{17)}$ proposed a numerical method, which is a combination of the volume-of-fluid (VOF) method for tracking gas-liquid interface ${ }^{18)}$ and the discrete particle model (DPM) for tracking discrete particles, ${ }^{19)}$ to simulate the bubble-particle interaction. In their two-dimensional simulations of single bubbles, glass particles of $0.8 \mathrm{~mm}$ in diameter and 2500 $\mathrm{kg} / \mathrm{m}^{3}$ in density were transported upward by the bubble wake and the wake entrainment process agreed with that observed in an experiment. ${ }^{20)} \mathrm{Xu}$ et al. ${ }^{21)}$ carried out threedimensional VOF-DPM simulations of single bubbles rising through stagnant liquid including particles. They investigated the effects of bubble diameter and particle diameter on the efficiency of the upward transportation of particles by bubble wake. The numerical predictions showed that the transportation rate of particles per a bubble increases with bubble size. The wake entrainment effect on particle motion was experimentally investigated by Yang et al. ${ }^{22)}$ Single bubbles were continuously injected from the bottom of a liquid pool and the rate of capture of particles by bubble wake was evaluated from video images. The particle motion in the particle-bubble wake interaction was classified into (1) approaching and passing into a wake boundary zone, (2) passing into a rising zone of wake, and (3) going on floating up or escaping from the rising zone. Their study focused on the identification of the wake entrainment process, so that the particle removal rate coefficient was not investigated.

Experiments on the removal rate coefficient in bubbly flows were carried out by Arai. ${ }^{23)} \mathrm{He}$ used various particles having different wettability with the contact angle ranging from 80 to 94 degree. The bubble and particle sizes were about $2 \mathrm{~mm}$ and $10 \mu \mathrm{m}$, respectively. Particles were dispersed in bubbly flows in a cylindrical column and were overflowed from the column top. He evaluated the removal rate coefficient by measuring the number concentration of particles in the column. The removal rate coefficient for hydrophilic particles was much smaller than that for hydrophobic particles, and therefore, he concluded that the inclusion removal by bubble injection does not efficiently work for hydrophilic slag inclusions. However in the actual bubbling system for molten steel bubbles and slag particles can be several times larger than those in his experiments, and our knowledge on the inclusion removal for hydrophilic particles in bubbly flows is still insufficient.

Particle removal experiments were carried out in this study for hydrophilic particles of $100 \mu \mathrm{m}$ diameter in bubbly flows consisting of bubbles of about $5 \mathrm{~mm}$ in diameter. The removal rate coefficient was evaluated using a measurement method similar to Arai's experiment. The mean bubble diameter was varied from 4 to $6 \mathrm{~mm}$ to investigate the effect of bubble size on the removal rate.

\section{Experimental}

\subsection{Experimental Setup and Conditions}

Figure 1 shows the experimental setup. The test section was the water tank, whose dimensions were $240 \times 210 \times$ $72 \mathrm{~mm}$ in width, height and depth. Mixture of water and particles was filled in the tank. The water temperature was kept at $25 \pm 1^{\circ} \mathrm{C}$ throughout the experiments. The air dif- fuser plate was mounted at the bottom of the tank. Stainless tubes were flash mounted on the diffuser plate as shown in Fig. 2 and they were placed inside the air chamber. Air was supplied from the compressor (HITACHI, OILFREE SCROLL-2.2) and flowed into the water tank through the mass flow controller (KOFLOC, Model3660), the air chamber and the tubes. The tube length was $160 \mathrm{~mm}$. The long tubes caused large pressure drops, resulting in uniform bubbling. ${ }^{24,25)}$

Spherical particles (Fuji-Silysia Chemical, CARiACT Q-10, porous silica) were used for inclusion. The particles were hydrophilic and were well dispersed in water. Orvalho et al. $^{26)}$ investigated the particle properties in detail. The particle size distribution had a dominant peak around $100 \mu \mathrm{m}$, and the mean diameter and the standard deviation were 103 $\mu \mathrm{m}$ and $15 \mu \mathrm{m}$, respectively. Initially the tank was empty and air was continuously injected at a constant gas volume flow rate, $Q_{G}$. Particles of the total mass, $M_{0}$, of $0.30 \mathrm{~kg}$ were pre-mixed with water and the water-particle mixture was poured into the tank while keeping the air injection. The mixture supply was stopped when the free surface

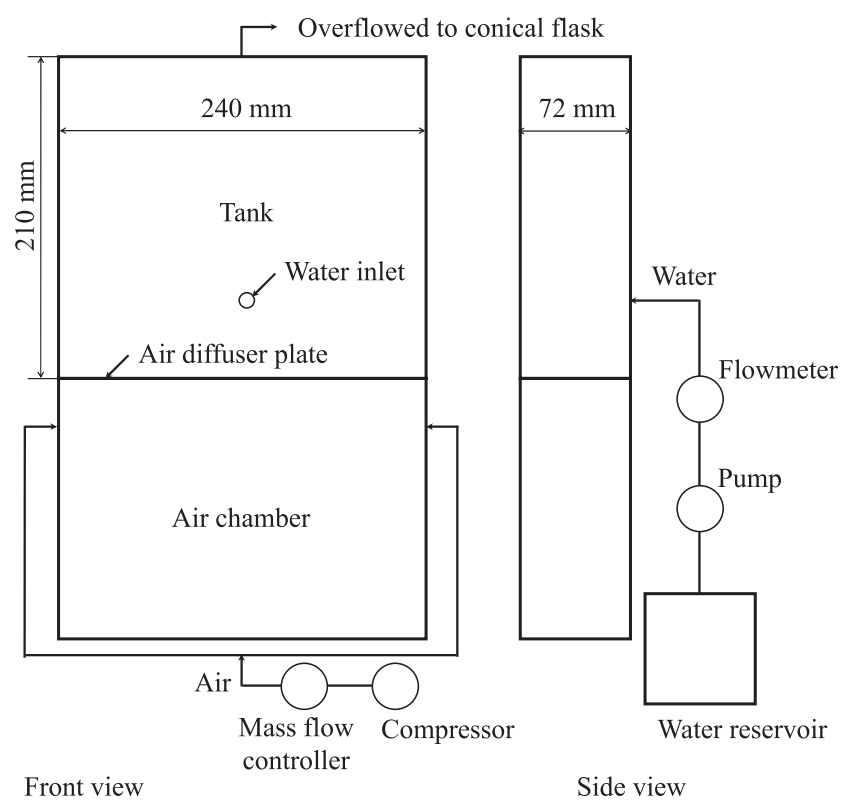

Fig. 1. Experimental setup.

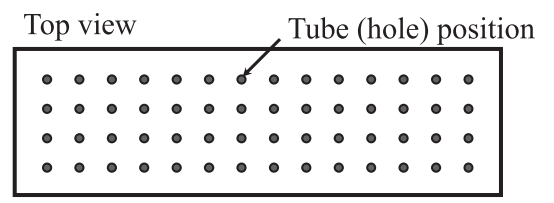

Front view

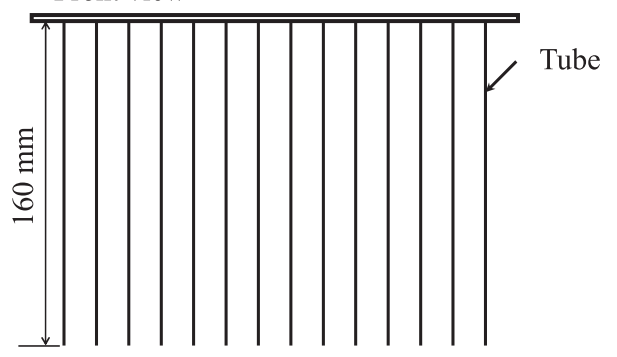

Fig. 2. Diffuser plate with tubes (Plate L). 
reached the top of the tank. In the actual molten steel in the tundish, inclusions transported upward are captured in a slag layer at the free surface. On the other hand, in the water tank in the present experiment, particles reached the free surface can go back to the bulk liquid while riding on the liquid circulation, and therefore, we need a way to collect particles in the vicinity of the free surface to evaluate the particle removal rate. Arai ${ }^{23)}$ supplied water into a tank filled with a water-particle mixture in his particle removal experiments. The water supply caused an overflow of the mixture from the top of the tank. Collecting particles in the overflowed mixture enabled him to evaluate the particle removal rate. We also used the mixture overflow. Water for overflow was filled in the reservoir (Fig. 1) and was kept at a constant temperature by using a heater (Hakko-Denki, AWA1510, DGC1151). Water was supplied from the reservoir into the tank at a constant liquid volume flow rate, $Q_{L}$, using the pump (IWAKI, MD-6K) and the flow rate was measured using the flowmeters (Tokyo-Keiso, F06-408813; Nippon-Flowcell, NSP-1-RC1/4-L). The water inlet port of $12 \mathrm{~mm}$ in diameter was mounted at the center of the tank in the width direction and $50 \mathrm{~mm}$ above the plate. Particles overflowed with water were captured using conical flasks.

Three kinds of air diffuser plates were used to vary bubble size. The diffuser plate shown in Fig. 2 has 56 holes made of the tubes, which were evenly positioned at the pitch of 16 and $14.4 \mathrm{~mm}$ in the width and depth directions, respectively. The inner diameters of the tubes were $0.70 \mathrm{~mm}$. The numbers of tubes of the other plates were 80 and 115 . The configurations of the plates are summarized in Table 1. Since the gas flow rate from each hole decreases with increasing the total number of holes while keeping $Q_{G}$, the bubble size is expected to decrease by changing the number of holes from 56 to 115 . Hereafter the diffuser plates with 56 $(4 \times 14), 80(5 \times 16)$ and $115(5 \times 23)$ holes are therefore referred to as Plate L, M and S, respectively.

The values of $Q_{G}$ were $2.33 \times 10^{-4}, 2.83 \times 10^{-4}$, and $3.33 \times$ $10^{-4} \mathrm{~m}^{3} / \mathrm{s}$, for which the gas superficial velocities, $J_{G}=Q_{G} / A_{T}$, were $0.0135,0.0164$ and $0.0193 \mathrm{~m} / \mathrm{s}$, respectively, where $A_{T}$ is the horizontal cross-sectional area of the tank. These conditions are referred to as Low, Medium and High $Q_{G}$ in the following. The $Q_{W}$ was $3.0 \times 10^{-5} \mathrm{~m}^{3} / \mathrm{s}$ and the liquid volume flux, $J_{L}=Q_{L} / A_{T}$, was $1.74 \mathrm{~mm} / \mathrm{s}$. The effects of $Q_{W}$ will be discussed later.

The true density (solid density), $\rho_{P}$, and the apparent density of particles were 2050 and $1480 \mathrm{~kg} / \mathrm{m}^{3}$, respectively. The former was evaluated by measuring the mass and volume of a water-particle mixture, and the latter was evaluated from the settling velocity of particles in stagnant water and Stokes' drag law. The true density of oxides is smaller than

Table 1. Plate configuration.

\begin{tabular}{cccc}
\hline & Plate S & M & L \\
\hline Number of tubes & 115 & 80 & 56 \\
Inner (hole) diameter [mm] & 0.51 & 0.58 & 0.70 \\
Pitch in width direction [mm] & 10 & 14 & 16 \\
Pitch in depth direction $[\mathrm{mm}]$ & 12 & 12 & 14.4 \\
\hline
\end{tabular}

that of molten steel, but we used particles heavier than water to make the evaluation of the removal rate easy. Terminal velocities of particles in stagnant water were preliminary measured from high-speed video images. Particles were put into stagnant water through the free surface. A high-speed video camera (PHOTRON, SA-X2, $60 \mathrm{fps}$ ) mounted on a microscope (NIKON, SMZ800) was used to observe particles falling through water. The measurement position was $50 \mathrm{~mm}$ below the free surface. The sampling number was 70 to obtain an accurate mean value. The mean terminal velocity was $2.64 \mathrm{~mm} / \mathrm{s}$. It should be noted that the terminal velocity is larger than $J_{L}$, and therefore, particles would fall down even with water supply from the sidewall of the tank if no bubbles were injected in the tank.

\subsection{Evaluation of Particle Removal Rate Coefficient}

The time evolution of the total number of particles, $N_{P}$, in the liquid phase is governed by the following first-order linear ordinary differential equation: ${ }^{12}$ )

$$
\frac{\mathrm{d} N_{P}}{\mathrm{~d} t}=-K N_{P}
$$

where $K$ is the reduction rate coefficient, and $t$ the time. The validity of this form of the differential equation will be examined later. Arai ${ }^{23)}$ used overflow of water to evaluate $K$. He therefore divided $K$ into the following two parts:

$$
K=k_{B}+k_{L}
$$

where $k_{B}$ is the removal rate coefficient representing the contribution of bubbles, and $k_{L}$ the contribution of water overflow, which can be evaluated as

$$
k_{L}=\frac{Q_{L}}{V_{T}\left(1-\varepsilon_{G}\right)}
$$

where $V_{T}$ is the tank volume, and $\varepsilon_{G}$ the gas holdup. In Eq. (3), the distributions of the gas and liquid phase fractions are assumed to be uniform in the system. A particle heavier than the liquid falls down relative to the liquid phase, and therefore, the relative particle settling velocity, $U_{P}$, can have a negative contribution to $K$. This effect was not accounted for in the evaluation of $K$ in Arai's experiments since it could be small because of small particle diameters $(10 \mu \mathrm{m})$ and of the relative density close to unity. In the present experiment, the particle diameter is however $100 \mu \mathrm{m}$, so that $U_{P}$ is not small and the settling motion of particles can affect $K$. Hence we take into account the particle settling effect on $K$ as

$$
K=k_{B}+k_{L}+k_{F}
$$

where

$$
k_{F}=\frac{U_{P} A_{T}}{V_{T}}
$$

Here $U_{P}<0$ for particles falling relative to the liquid phase. The $k_{B}$ should therefore be regarded as the removal rate coefficient for neutrally-buoyant particles. Integrating Eq. (1) yields

$$
N_{P}=N_{P 0} e^{-K\left(t-t_{0}\right)}
$$

where $N_{P 0}$ is $N_{P}$ at the initial time $t_{0}$. The $K$ is therefore 
given by

$$
K=-\frac{\ln \left(N_{P} / N_{P 0}\right)}{t-t_{0}}
$$

Substituting Eq. (4) into Eq. (7) yields the following expression for $k_{B}$ :

$$
k_{B}=-\frac{\ln \left(\frac{N_{P}}{N_{P 0}}\right)}{t-t_{0}}-\frac{Q_{L}}{V_{T}\left(1-\varepsilon_{G}\right)}-\frac{U_{P} A_{T}}{V_{T}}
$$

Since $M_{P}=N_{P} \rho_{P} \frac{\pi d_{P}^{3}}{6}$ and $M_{P 0}=N_{P 0} \rho_{P} \frac{\pi d_{P}^{3}}{6}$, we obtain

$$
k_{B}=-\frac{\ln \left(\frac{M_{P}}{M_{P 0}}\right)}{t-t_{0}}-\frac{Q_{L}}{V_{T}\left(1-\varepsilon_{G}\right)}-\frac{U_{P} A_{T}}{V_{T}}
$$

This is the basis of $k_{B}$ evaluation. It should be noted that the second term in the RHS for the water overflow is based on the assumption that particle removal uniformly takes place over the cross section. This did not hold in the experiments and $Q_{L}$ still had some effects on $k_{B}$ even after subtraction of the second term as described in the next section. We therefore introduced the extra $Q_{L}$ effect, $\widehat{k_{L}}$, based on the experimental data of $k_{B}$ for several $Q_{L}$.

$$
\begin{aligned}
k_{B} & =K-k_{L}-k_{F}-\widehat{k_{L}} \\
& =-\frac{\ln \left(\frac{M_{P}}{M_{P 0}}\right)}{t-t_{0}}-\frac{Q_{L}}{V_{T}\left(1-\varepsilon_{G}\right)}-\frac{U_{P} A_{T}}{V_{T}}-\widehat{k_{L}}
\end{aligned}
$$

\section{Results and Discussion}

\subsection{Characteristics of Bubbly Flows}

In experiments on removal of fine particles in bubbly flows, it is important to understand the characteristics of the bubbly flows, i.e. the bubble diameter, the gas holdup and so on. Experiments on bubbly flows without particles were first carried out to measure the above-mentioned quantities.

Bubble diameters were measured from images obtained by using a high-speed video camera (Photron, SA-X2, 60 fps). Recordings were carried out at $110 \mathrm{~mm}$ above the tank bottom and at three positions, i.e. 40,120 and $200 \mathrm{~mm}$ from the sidewall of the tank. The sphere-volume-equivalent bubble diameter was calculated with the assumption of ellipsoidal bubble shape. 300 bubbles were randomly selected in each condition. The mean bubble diameter, $d_{B}$, was calculated by taking number average for the selected bubbles. Figure 3 shows the bubble size distributions for (a) Plate $\mathrm{S}$, (b) Plate M, and (c) Plate $\mathrm{L}$ at $J_{G}=0.016 \mathrm{~m} / \mathrm{s}$. The bubble size distribution shifts from small to large diameters from left (Plate S) to right (Plate L). Table 2 shows the mean bubble diameter with each plate for three gas flow rate conditions. The mean bubble diameter changes even at the same gas flow rate by changing the diffuser plate. Most of the bubbles are within $\pm 1.5 \mathrm{~mm}$ from the mean diameters. Davidson and Amick ${ }^{27)}$ proposed the following empirical correlation for the bubble frequency for bubbles generated from an orifice:

$$
f_{B}=\frac{12.26 Q_{O}^{0.13}}{d_{O}^{0.43}}
$$

where $Q_{O}$ is the gas volume flow rate from an orifice and $d_{O}$ the orifice diameter. The mean bubble diameter is given by

$$
d_{B}=\sqrt[3]{\frac{6 Q_{O}}{\pi f_{B}}}
$$

By substituting the gas flow rate from each hole and the hole diameter into Eq. (12), $d_{B}$ were calculated and were compared with the present data as shown in Fig. 4. They are in good agreement, which means that the bubbling regime in the present experiments is inertia dominant and the surface tension does not play any role in bubble size.
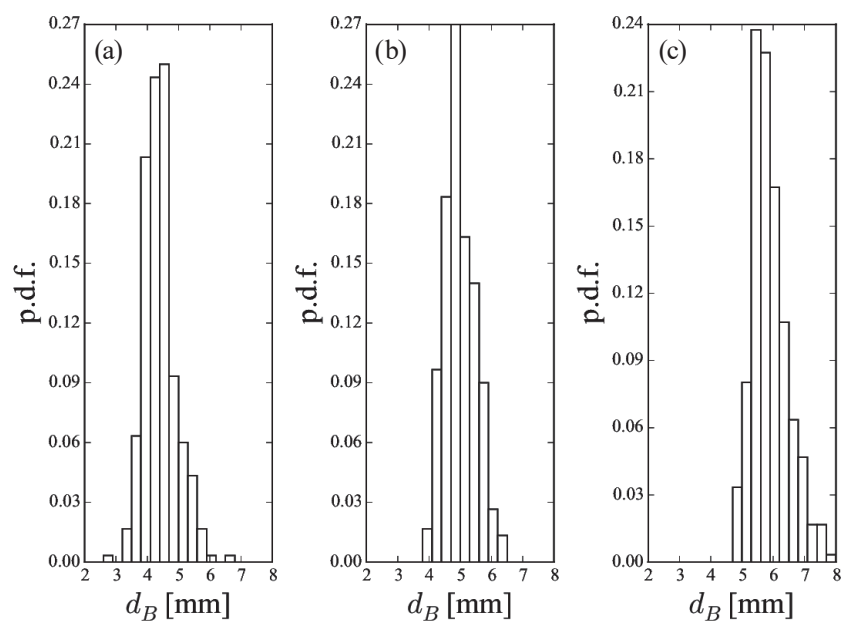

Fig. 3. Bubble size distribution (Low $Q_{G}\left(J_{G}=0.016 \mathrm{~m} / \mathrm{s}\right)$ ). (Plate, Mean bubble diameter $[\mathrm{mm}])(\mathrm{a})(\mathrm{S}, 4.4)(\mathrm{b})(\mathrm{M}, 5.0)(\mathrm{c})(\mathrm{L}$, 5.9).

Table 2. Mean bubble diameter [mm].

\begin{tabular}{cccc}
\hline$Q_{G} \times 10^{-4}\left[\mathrm{~m}^{3} / \mathrm{s}\right]$ & Plate S & $\mathrm{M}$ & $\mathrm{L}$ \\
\hline 2.3 & 4.1 & 4.7 & 5.6 \\
2.8 & 4.4 & 5.0 & 5.9 \\
3.3 & 4.7 & 5.3 & 6.1 \\
\hline
\end{tabular}

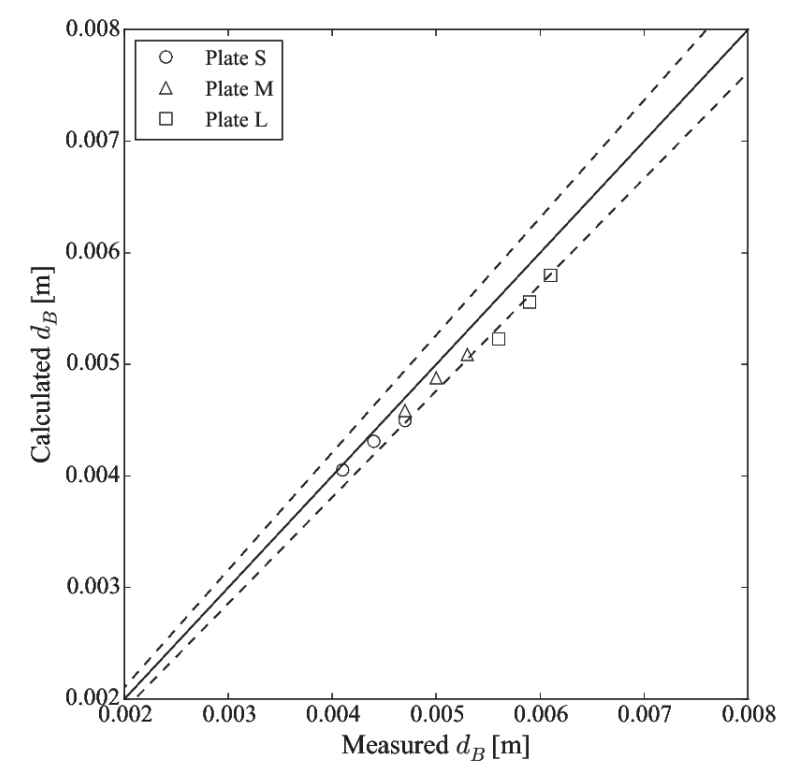

Fig. 4. Mean bubble diameter compared with Davidson-Amick correlation (Dashed lines: $\pm 5 \%$ error). 
The total bubble volume in the tank was obtained by measuring the amount of water for filling up the tank while aeration. The gas holdups, $\varepsilon_{G}$, are shown in Table 3. The values are several percent in all the cases. The total numbers, $N_{B}$, of bubbles were calculated from $\varepsilon_{G}$ and $d_{B}$ as shown in Fig. 5. The $N_{B}$ slightly increases with $Q_{G}$. Comparing $N_{B}$ of dif-

Table 3. Gas holdup.

\begin{tabular}{cccc}
\hline$Q_{G} \times 10^{-4}\left[\mathrm{~m}^{3} / \mathrm{s}\right]$ & Plate S & $\mathrm{M}$ & $\mathrm{L}$ \\
\hline 2.3 & 0.052 & 0.051 & 0.052 \\
2.8 & 0.069 & 0.067 & 0.071 \\
3.3 & 0.086 & 0.085 & 0.090 \\
\hline
\end{tabular}

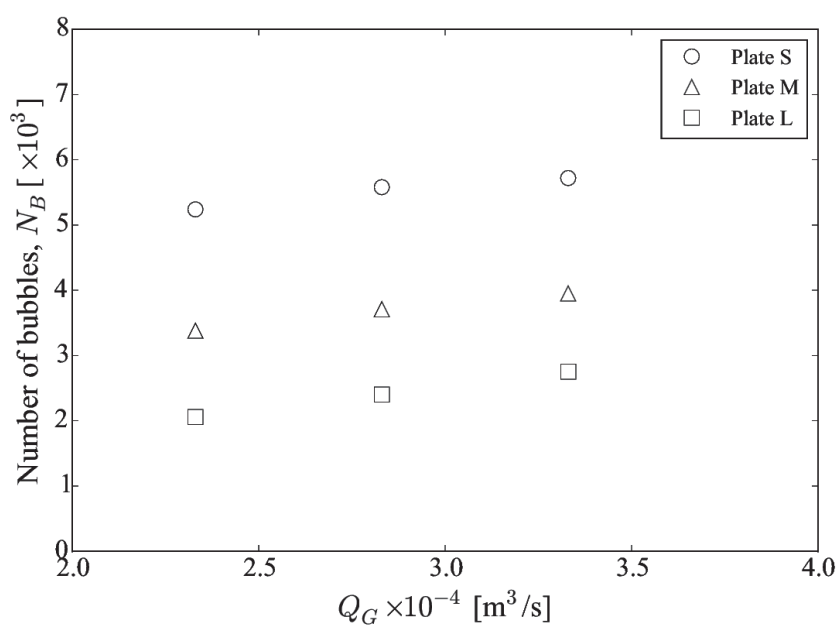

Fig. 5. Total number of bubbles, $N_{B}$, in tank.

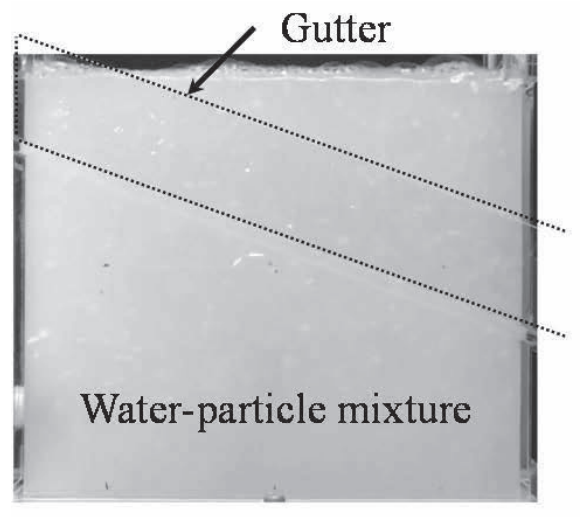

$\mathrm{t}=0 \mathrm{~s}$

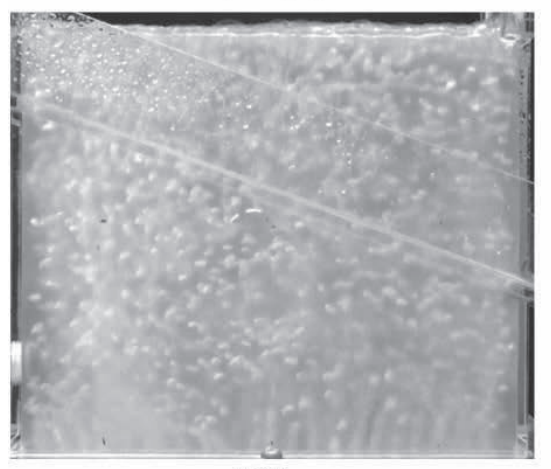

$480 \mathrm{~s}$ ferent plates shows that $N_{B}$ approximately proportional to the number of holes.

\subsection{Removal Process and Removal Rate Coefficient}

Figure 6 shows front images of the bubbly flow at Low $Q_{G}$. Initially $\left(t=t_{0}=0\right)$ bubbles in the tank are invisible due to the presence of fine particles. The uniform color implies that particles are well dispersed and the particle concentration is almost uniform. The dotted lines represent a gutter, which surrounds the tank to lead overflowed water to the conical flask as shown in the image at $240 \mathrm{~s}$. The visibility of the flow increases with $t$ as a consequence of particle removal. If there were no bubbles, the particles settling velocity could be $U_{P}+J_{L} \sim-0.9 \mathrm{~mm} / \mathrm{s}$, for which particle sedimentation at the bottom of the tank would take $270 \mathrm{~s}$ for the tank height of $240 \mathrm{~mm}$. Particles are still uniformly dispersed even in the image at $240 \mathrm{~s}$, and therefore, bubbles effectively transport particles upward. The liquid phase becomes transparent at $720 \mathrm{~s}$. Hence the particle removal has been completed.

Figure 7 shows the ratio, $\ln \left(M_{P} / M_{P 0}\right)$, of the total mass of particles to the initial total mass. The $\ln \left(M_{P} / M_{P 0}\right)$ linearly decreases with increasing $t-t_{0}$. Hence $K=-\ln \left(M_{P} / M_{P 0}\right) /(t-$ $\left.t_{0}\right)$ is constant and the model, Eq. (1), is valid. The $K$ was evaluated from a regression line to the data.

Figure 8 shows $K-k_{L}-k_{F}$ measured at various $Q_{W}$. This quantity depends on $Q_{W}$. Hence the effect of the water inflow cannot be entirely removed with $k_{L}$ only although $k_{L}$ was introduced in Eq. (10) to eliminate that effect. The decrease in $K-k_{L}-k_{F}$ with increasing $Q_{W}$ implies that the motion of water horizontally injected from the tank sidewall disturbed the upward motion of particles even at small

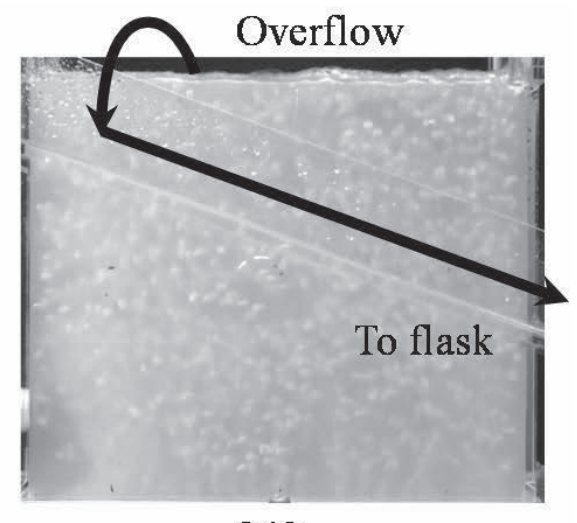

$240 \mathrm{~s}$

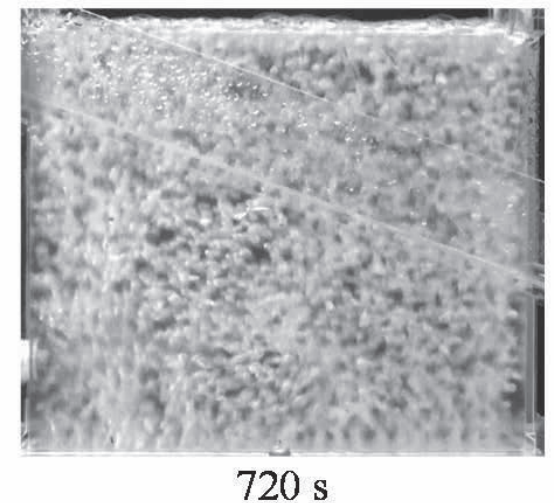

Fig. 6. Particle removal process $\left(Q_{W}, Q_{G}\right)=\left(3.0 \times 10^{-5}, 2.3 \times 10^{-4}\right)\left[\mathrm{m}^{3} / \mathrm{s}\right]$, Plate $\left.\mathrm{S}\right)$. 


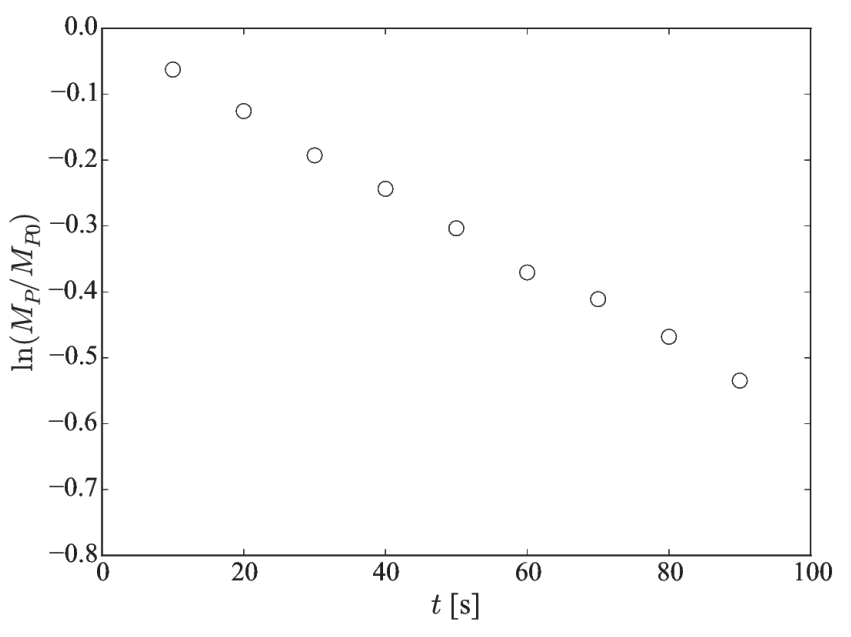

Fig. 7. Change in total particle weight, $\ln \left(M_{P} / M_{P 0}\right)$, at $\left(Q_{W}, Q_{G}\right)=$ $\left(3.0 \times 10^{-5}, 2.3 \times 10^{-4}\right)\left[\mathrm{m}^{3} / \mathrm{s}\right]$ with Plate $\mathrm{S}$.

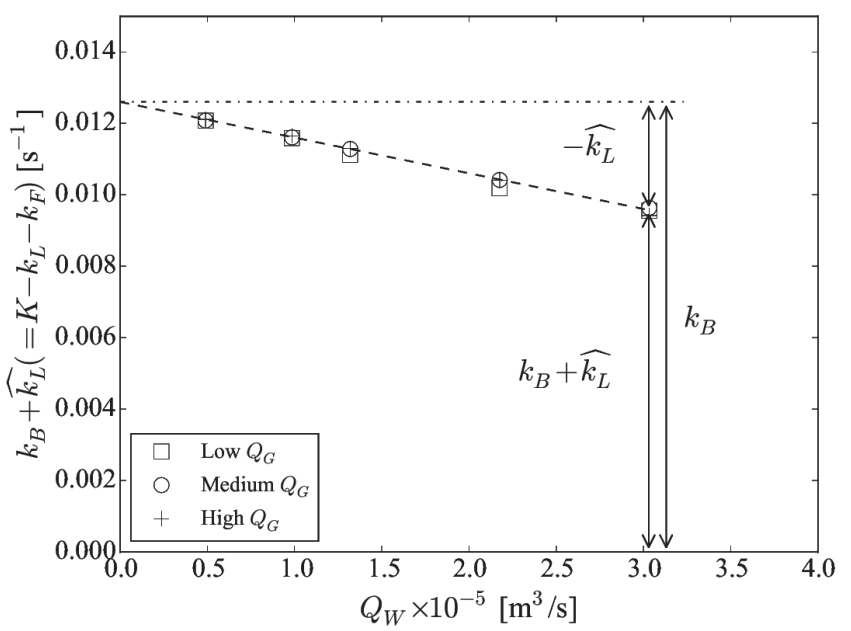

Fig. 8. Additional liquid inflow effect (Plate S).

$Q_{W}$. This water inlet effect can therefore be expressed as $k_{L}+\widehat{k_{L}}\left(Q_{W}\right)$ and $\widehat{k_{L}}\left(Q_{W}\right)$ was evaluated from the regression line shown in Fig. 8.

\subsection{Effects of Gas Flow Rate and Bubble Diameter on $\boldsymbol{k}_{B}$}

Figure 9 shows $k_{B}$ for all the conditions (three plates and three $Q_{G}$ ). The positive values of $k_{B}$ mean that bubbles have abilities to bring hydrophilic fine particles upward even though the particles do not adhere to the bubble interfaces. The particle transportation can be attributed to the bubble wake as discussed for single bubbles in literature, ${ }^{17,21,22)}$ i.e. particles collide with bubble wake are entrained into the bubble wake at a certain probability and dragged upward while riding on the liquid flow in the wake. However as pointed out by Yang et al. ${ }^{22)}$ particles may escape from the bubble wake after traveling some distances. In addition, bubble paths in the present range of $d_{B}$ oscillate and bubble wakes are shed when a bubble changes its direction of motion, ${ }^{28-30)}$ resulting in many particle shedding from the near wake region. Such escaped particles however collide with wakes of trailing bubbles and entrained again. The $k_{B}$ is almost independent of both plate types and $Q_{G}$, in other words neither $d_{B}$ nor $N_{B}$ affects $k_{B}$.

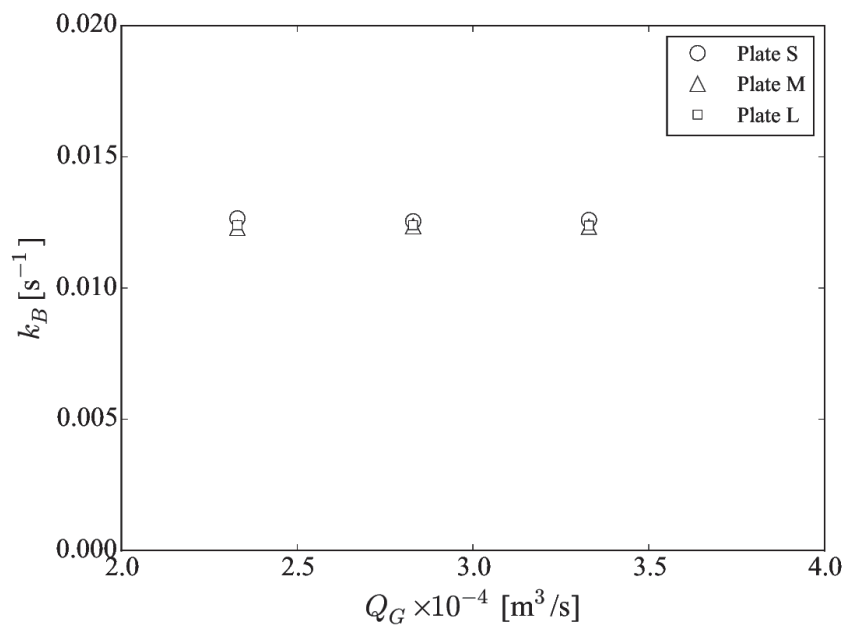

Fig. 9. Removal rate coefficient $k_{B}$.

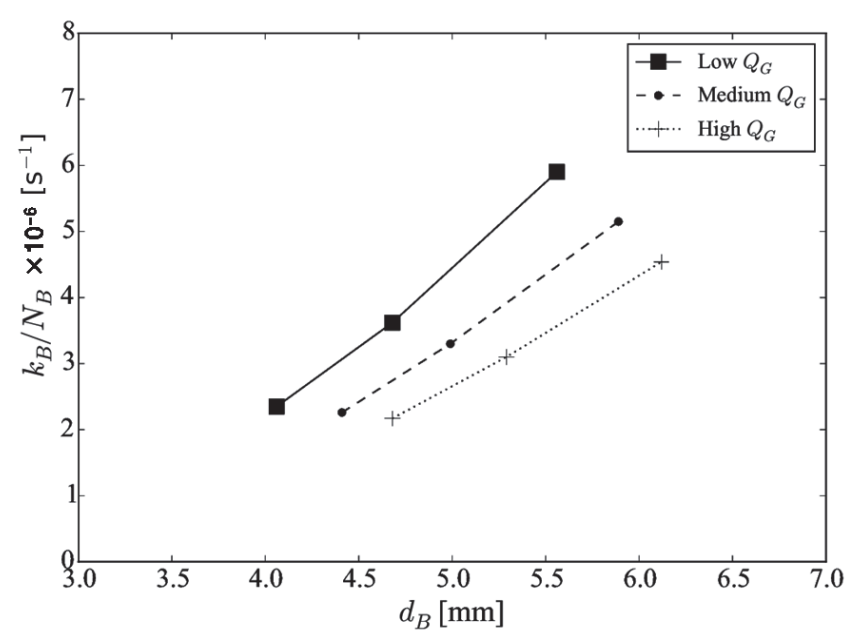

Fig. 10. $k_{B}$ per a bubble, $k_{B} / N_{B}$.

Figure 10 shows $k_{B}$ divided by $N_{B}$, i.e. the removal rate coefficient per a bubble. The coefficient increases with $d_{B}$ at each $Q_{G}$. This might be due to the increase in the wake volume with increasing the bubble Reynolds number. ${ }^{31)}$ On the other hand, the coefficient decreases with increasing $Q_{G}$ while keeping $d_{B}$. If all the bubbles in the tank are evenly positioned at a pitch of $l$ in all the directions, $l$ is given by

$$
l=\sqrt[3]{\frac{V_{T}}{N_{B}}}
$$

The upward transportation of particles by a bubble is to be effective in the volume, $V_{w}$, of the water-particle mixture between the bubble and its trailing bubble. Approximating $V_{w}$ as the cylinder of the height, $l-d_{B}$, and the diameter of $d_{B}$ yields

$$
V_{w}=\left(\sqrt[3]{\frac{V_{T}}{N_{B}}}-d_{B}\right) \frac{\pi d_{B}^{2}}{4}
$$

This volume decreases with increasing $N_{B}$ at constant $d_{B}$. As shown in Table 2, $d_{B}$ at Low $Q_{G}$ of Plate $\mathrm{M}$ and that at High $Q_{G}$ of Plate $\mathrm{S}$ are the same $(4.7 \mathrm{~mm})$, whereas $N_{B}$ are 3380 and 5720 , respectively, as shown in Fig. 5. $V_{w}=$ $9.6 \times 10^{-8}$ and $6.8 \times 10^{-8} \mathrm{~m}^{3}$ for the former and the latter 
cases, respectively. The smaller $V_{w}$ in the latter could be one of the reasons of the small transportation efficiency by each bubble, $k_{B} / N_{B}$, at High $Q_{G}$.

In summary, the efficiency of particle removal by each bubble increases with bubble diameter, whereas the increase in the number of bubbles deteriorates the efficiency due to the reduction of the wake volume effective for particle transportation.

\section{Conclusion}

Experiments on removal of hydrophilic fine particles in bubbly flows were carried out. Air and water at room temperature and atmospheric pressure were used for the gas and liquid phases, respectively. Silica particles of $100 \mu \mathrm{m}$ in diameter were used for inclusion. Bubbles were injected into water-particles mixtures in a rectangular tank and the amount of particles included in the mixture overflowed from the tank was measured to evaluate the removal rate coefficient. Three air diffuser plates and three gas volume flow rates were used to realize various conditions of bubble diameter and the number of bubbles. The data of the removal rate coefficients revealed that bubbly flows can transport fine particles upward. Because of the hydrophilic nature of the silica particles, the transportation of particles is caused not by attachment to the bubble interface but by the motion of bubble wake. Since the wake volume increases with the bubble Reynolds number (size and rise velocity), the removal efficiency for each bubble increases with bubble size. On the other hand, the increase in the number of bubbles decreases the efficiency for each bubble since the wake region effective for particle transportation reduces as the number of bubbles increases.

\section{Acknowledgement}

The authors would like to express their thanks to Mr. Jiayi Chen and Mr. Hikaru Ido for assistance in the experiments.

\section{REFERENCES}

1) Y. Miki and B. G. Thomas: Metall. Mater. Trans. B, 30 (1999), 639.

2) D. Y. Sheng, M. Soder, P. Jonsson and L. Jonsson: Scand. J. Metall., 31 (2002), 134.

3) H. Yamamura, K. Amada, K. Takase and T. Matsumiya: Tetsu-toHagané, 98 (2012), 650.

4) Y. Xu, M. Ersson and P. G. Jonsson: Metall. Mater. Trans. B, 46 (2015), 2628.

5) Y. Xu, M. Ersson and P. G. Jonsson: Steel Res. Int., 86 (2015), 1289.

6) P. Diaz-Penafiel and G. S. Dobby: Miner. Eng., 7 (1994), 465.

7) K. L. Sutherland: J. Phys. Chem., 52 (1948), 394.

8) D. Reay and G. A. Ratcliff: Can. J. Chem. Eng., 51 (1973), 178.

9) W. Pan, K. Uemura and S. Koyama: Tetsu-to-Hagané, 78 (1992), 1361.

10) J. S. Kim, M. Kawakami and K. Tanida: Tetsu-to-Hagané, 81 (1995), 167.

11) L. Wang, H. G. Lee and P. Hayes: ISIJ Int., 36 (1996), 7.

$12)$ R. H. Yoon and L. Mao: J. Colloid Interface Sci., 181 (1996), 613

13) X. Zheng, P. C. Hayes and H. G. Lee: ISIJ Int., 37 (1997), 1091

14) L. T. Wang, Q. Y. Zhang, S. H. Peng and Z. B. Li: ISIJ Int., 45 (2005), 331.

15) L. Zhang, J. Aoki and B. G. Thomas: Metall. Mater. Trans. B, 37 (2006), 361.

16) L. R. Flint and W. J. Howarth: Chem. Eng. Sci., 26 (1971), 1155.

17) Y. Li, J. Zhang and L. S. Fan: Chem. Eng. Sci., 54 (1999), 5101.

18) C. W. Hirt and B. D. Nichols: J. Comput. Phys., 39 (1981), 201

19) P. A. Cundall and O. D. L. Strack: Geotechnique, 29 (1979), 47.

20) T. Miyahara, K. Tsuchiya and L. S. Fan: AIChE J., 35 (1989), 1195.

21) Y. Xu, M. Ersson and P. G. Jonsson: ISIJ Int., 56 (2016), 1982.

22) H. L. Yang, P. He and Y. C. Zhai: ISIJ Int., 54 (2014), 578.

23) H. Arai: Ph.D. thesis, Tohoku University, (2010), https://tohoku.repo. nii.ac.jp/?action=repository_uri\&item_id=72053, (accessed 201802-18).

24) C. Garnier, M. Lance and J. L. Marie: Exp. Therm. Fluid Sci., 26 (2002), 811 .

25) M. H. Mohd. Akbar, K. Hayashi, D. Lucas and A. Tomiyama: Chem. Eng. Sci., 104 (2013), 166.

26) S. Orvalho, M. Hashida, M. Zednikova, P. Stanovsky, M. C. Ruzicka, S. Sasaki and A. Tomiyama: Chem. Eng. Sci., 351 (2018), 799.

27) L. Davidson and E. H. Amick, Jr.: AIChE J., 2 (1956), 337.

28) C. Brucker: Phys. Fluids, 11 (1999), 1781

29) A. Serizawa and A. Tomiyama: Multiphase Sci. Technol., 15 (2003), 79.

30) I. Zun, M. Perpar, J. Gregorc, K. Hayashi and A. Tomiyama: Chem. Eng. Sci., 72 (2012), 155.

31) L. S. Fan and K. Tsuchiya: Bubble Wake Dynamics in Liquids and Liquid-Solid Suspensions, Butterworth-Heinemann, Stoneham, (1990). 